\title{
Tramas Criativas (ou o que não nos deiXam Ver as imagens)
}

Humberto Martins ${ }^{1}$ e Sofia Sampaio ${ }^{2}$

\section{TEXTO E IMAGEM: COMPLEMENTARIDADES}

Qual trama de um tear que esconde do lado avesso pontas soltas e fios emaranhados, os filmes escondem textos, etapas, escolhas, desejos, impulsos, verdades, ficções - numa palavra, escondem „autores“; ou, se preferirmos, revelam-nos sombras, rastos, fragmentos de homens e mulheres em processo de criação. São os lados „avessos“ destes processos criativos tornados públicos no seu „lado direito“ (enquanto filmes vistos) que pedimos aos realizadores presentes na Mostra de Filme Etnográfico do V Congresso da Associação Portuguesa de Antropologia para nos mostrarem. A pretensão, nossa, não deixa de ser ingénua por presumirmos a inexistência de outras agencialidades, nomeadamente durante o processo de edição, em que a negociação entre os lados visível e não-visível dos filmes teve lugar. Voltar aos filmes para os desfiar ou pegar nas pontas que ficam é sempre um trabalho difícil; na verdade, significa voltar a um novo processo editorial, a um novo filme - a um filme no seu „alter-ego“ ou a um filme „amadurecido“ pelos visionamentos e comentários, em festivais e mostras (como a nossa), num acumular de traços e marcas que lhe vão construindo o seu carácter de objecto, a sua „objecthood“, 3 e que os tornam coisas com „vida“ social no mundo - afirmando-as na sua agencialidade - perante „espectadorias"variadas.

Assim nasceu este número dos Cadernos de Arte e Antropologia, dedicado a uma mostra de filme etnográfico. Enquanto membros do júri de selecção, e depois de feitas as escolhas (não consensuais), achámos útil desafiar os realizadores a reflectir sobre as suas obras a partir de uma „arqueologia“ e de uma „anatomia“ capazes de revelar e revisitar opções estéticas, antropológicas, fílmicas e idiossincráticas. Como um retorno à casa de partida para voltar a contar a história do seu filme, agora como estória de revelações, inquietações, dúvidas, dilemas. O que pedimos, na verdade, foi para nos entreabrirem a porta da sua sala de edição, para assim podermos (nós e

1 UTAD/CRIA-ISCTE, Vila Real e Lisboa, Portugal. Contacto: hmartins@utad.pt

2 CRIA-ISCTE, Lisboa, Portugal. Contacto: psrss@iscte.pt

3 Cf. Elizabeth Edwards, 2002 "Material Beings: objecthood and ethnographic photographs", Visual Studies, $17: 1,67-75$. 
muitos outros) espreitar como se faz e foi feito cada filme. Não é prática muito comum escrever sobre processos criativos a partir de um desafio lançado por uma revista científica com peer-review. ${ }^{4}$ De alguma forma, pode o realizador ser levado a pensar que o filme é um registo menor porque precisa de ser explicado, ou que apenas o texto pode garantir a cientificidade e antropologicidade necessárias à legitimação da sua abordagem. Não foi nem é de todo este o nosso entendimento; o desafio lançado visou a complementaridade dos dois registos e a sua transmutação em algo novo. Reconhecemos que texto escrito e imagem em movimento tecnologizada garantem-nos formas e produtos de representação da realidade social que são, não apenas diferentes, mas também (idealmente) contrastivos e alternativos, assegurando o estatuto de contraponto que dá o mote a este número especial. Por um lado, os cinco artigos seleccionados ensinam, se não directamente como se pode fazer antropologia através de imagens, pelo menos como lidar com os imprevistos e os imponderáveis do quotidiano - um pouco na esteira dos pressupostos malinowskianos que marcam a especificidade metodológica da antropologia. Ensinam-nos ainda a ver, dando-nos pistas para a apreciação destes filmes enquanto objectos artísticos.

O segundo propósito liga-se, precisamente, ao que Carlson designa por „apreciação estética do objecto artístico, "5 que pressupõe o conhecimento do autor e dos contextos histórico-culturais de produção da obra. Por outras palavras, ao inscrevermos o objecto artístico numa estória/ na história tornamo-nos capazes de o interpretar nos seus próprios termos. Apreciar significa, portanto, estar no domínio de conhecimento técnico, específico e concreto de como as coisas são/ foram feitas. Não visa tanto a aquisição cumulativa de competências técnicas específicas quanto a intensificação da própria experiência de visionamento através do recurso a pistas informativas que normalmente não aparecem nas imagens (apesar de o registo escrito abrir porta a leituras que desconhecem o filme). Esta é, aliás, uma questão central no campo dos estudos sobre o visual, que autores como John Berger, Nicholas Mirzoeff, Mieke Bal e W.J.T. Mitchell tanto discutiram e que, em última instância, nos remete para os conceitos de „modos de ver“, „regime escópico“ e „espectadoria“. Ou seja, a apreciação do objecto visual remete-nos para o pressuposto fundamental de que, por detrás do que é visível, está todo um domínio do invisível (melhor dizendo, do que não é mostrado), que importa considerar para percebermos as produções artísticas (os objectos de cultura visual) na sua plenitude.

Estamos também perante temas clássicos da antropologia visual, em particular relacionados com o filme etnográfico ou documental (embora os dois termos não designem uma e a mesma coisa ${ }^{6}$ ); ou seja, o que está em causa é a relação entre texto e imagem, por um lado, e o estatuto que a imagem pode ter no seio da disciplina, por outro, justamente num tempo de acentuada audiovisualização da nossa experiência no mundo e das formas de conhecimento que privilegiamos. ${ }^{7}$ Trata-se de uma questão não resolvida na antropologia, envolta em desconfianças mútuas entre quem privilegia formas de conhecer através das imagens produzidas e quem o faz principalmente através da escrita de texto. Neste sentido, a nossa proposta aponta para uma diplomacia do encontro epistemológico e metodológico entre texto e imagem sem nunca

4 O desafio foi feito aos dezasseis realizadores que viram os seus filmes escolhidos para a Mostra. Destes, apenas oito acederam. Houve artigos que foram recusados num primeiro momento e outros numa segunda fase, após avaliação pelos pareceristas.

5 Allen Carlson, 1993, "Appreciating Art and Appreciating Nature” in Salim Kemal e Ivan Gaskell (eds.) Landscape, Natural Beauty and the Arts, Cambridge, Cambridge University Press, 197-227.

6 Algo a que, todavia, não dedicaremos a nossa atenção neste artigo.

7 Humberto Martins, 2013, "Sobre o lugar e os usos das imagens na antropologia: notas críticas em tempos de audiovisualização do mundo”, Etnográfica, vol. 17 (2), 395-419. 
afirmar a primazia de um sobre o outro. Socorrendo-nos de uma metáfora culinária, diríamos que não pedimos reduções de produtos a outros: pedimos outros produtos. $\mathrm{E}$ aqui situamos um outro encontro - entre arte e antropologia (tema já abordado numa edição anterior desta revista $^{8}$ ) - porque na verdade, e recuperando um termo dos organizadores desse volume, tratamos também de „heterodoxias metodológicas“ plasmadas em produtos que escapam às normalidades convencionais da antropologia do texto escrito. E são de realizadores (e artistas), para além de antropólogos, que estes textos derivam, daí revelarem novas linguagens de escrita e de fuga aos cânones do texto antropológico escrito, sugerindo subjectividades e autoralidades que emergem em contraponto.

\section{Cinco textos, Cinco filmes}

São cinco os textos apresentados neste dossiê. Cada texto, diferente na forma e no conteúdo, diz respeito também a um objecto fílmico único e específico. Os cinco filmes que inspiram os cinco textos traduzem formas diferentes de abordagem etnográfica e opções estéticas e cinematográficas várias - em termos de narração, fotografia, som, duração, direcção, profundidade temporal, ritmo, e, porque não referi-lo, antropologicidade. ${ }^{9}$ Amaya Sumpsi fala-nos do seu filme «Meu Pescador, Meu Velho» (título modificado de «Apanhados na Rede», 58', 2012). Em „O documentário longitudinal: a importância de filmar com tempo“, a autora explora a passagem do tempo ao longo dos nove anos que o filme demorou a fazer - passagem essa que é sentida a três níveis ou dimensões: no aprofundamento (ou antropologização) do seu conhecimento sobre a comunidade; na sua própria transformação (nomeadamente, com a chegada à antropologia); na transformação física e social do espaço, da comunidade e dos indivíduos filmados.

Pedro Antunes conta-nos o processo por detrás do filme «P'ra Irem P'ró Céu» (22', 2013), no artigo intitulado „Insomnolências' e notas de campo do filme 'P'ra Irem P'ró Céu'“. Como o próprio refere, trata-se de um ensaio auto-reflexivo que tenta passar aos leitores a dimensão da invisibilidade que está presente na morte - no sentido do que não se vê e ao que não se acede senão por uma ritualização que o filme ajuda a activar, aproximando-se de um „cine-transe“, muito sugerido e explorado por Jean Rouch. Na esteira deste, Antunes crê que com as imagens conseguimos captar sentimentos, acções, manifestações que, de outra forma (entenda-se, através de abordagens convencionais), não conseguiríamos, num processo que também transforma o realizador e o faz entrar na performance do ritual e do acto de filmar.

Rodrigo Lacerda fala de «Thierry» $(17$ ’, 2012), um filme sobre um activista político francês e trabalhador sexual em Londres. No artigo "So, what do we talk about? O discurso político e a imagem corpórea em «Thierry»", o autor explora a noção de imagem corpórea proposta por David MacDougall (2006) ${ }^{10}$. O título do artigo é, aliás, elucidativo, assinalando a complexidade performativa da existência humana, aqui revelada no espaço instável entre discurso verbal e corpo filmado. Enquanto acesso „háptico“ privilegiado, o filme ajuda, num certo sentido, a recuperar a integralidade perdida nas abordagens que não mostram corpo, rosto, gestos, movimento e circunstâncias da vida.

8 Cadernos de Arte e Antropologia, vol. 2, no 1, 2013, dossiê 'Antropologia, etnografia e práticas artísticas', organizado por Sónia Vespeira de Almeida e Ilka Boaventura Leite.

9 A Mostra revelou também diferentes sensibilidades etnográficas por parte dos membros do júri.

10 David MacDougall, 2006, The Corporeal Image, Princeton, New Jersey, Princeton University Press. 
No artigo „Os Últimos Pioneiros: Memórias de um ritual“, Daniela Rodrigues traça o processo de construção do documentário com o mesmo nome, «Zadnji Pionirji» (ou os «Últimos Pioneiros», 11', 2012). O texto constitui uma memória descritiva - um memorando, no duplo sentido da palavra. Por um lado, revela-nos as etapas e os encontros pelos quais a realizadora foi passando (um percurso desencadeado por um item de cultura material - uma revista infantil comprada, ao acaso, num alfarrabista - e pontuado por outras „coisas“); por outro, mostra-nos o ritual de integração no Movimento Pioneiro da Jugoslávia de Tito e, associado àquele, as manifestações de uma nostalgia reflexiva em jovens adultos eslovenos. Rodrigues fala-nos de um „tempo perdido“ na Ex-Jugoslávia, recuperado a partir de um acesso frágil à memória de jovens pioneiros (os últimos), agora cidadãos da actual Eslovénia.

Finalmente, no artigo „Films, terrains et anthropologie: à propos d'images et d'écrits“, Fabienne Wateau propõe uma reflexão mais ampla sobre o lugar da antropologia visual na (sua) antropologia. O pano de fundo para esta reflexão são três documentários produzidos com diferentes intencionalidades e para diferentes fins; «Ma Parenté Au Village» (2011, 18'), exibido na mostra de filme etnográfico da APA, «La canne à mesurer l'eau» (ou «A cana de medir a água», 2006, 28') e «La pierre de partage de l'eau» (ou «O marco da água», 2003, 11'). Wateau debruça-se sobre as virtudes epistemológicas do filme e as inter-relações com a „abordagem convencional", a fim de reivindicar a apreciação de um filme em si mesmo e não pelos quadros conceptuais de uma antropologia dependente do texto escrito. Ou seja, a fim de reivindicar um estatuto de autonomia relativa para cada um destes produtos/objectos de representação.

Os cinco filmes são obras relativamente iniciáticas - umas mais do que outras - o que, aliás, levou quase todos os autores a situarem-se numa espécie de história privada dos seus filmes, trama de processos e opções metodológicas. Este é um tema recorrente, explorado através de uma abordagem dual: por um lado, conta-se a história do processo fílmico que deu origem ao filme apresentado na mostra (no caso de Wateau, estendendo-se a outros dois trabalhos). É aqui que surgem os imponderabilia malinowskianos, referidos por Antunes, ou a não-menos importante questão da discrepância entre a demanda do filme etnográfico „ideal“ e as dificuldades encontradas no „terreno“ (que tanto pode corresponder ao momento da toma de imagens como da montagem, ou mesmo da projecção perante os interlocutores ou outros públicos), colocada por Wateau. Por outro lado, faz-se referência à história relacional com a câmara de filmar e o documentário que, no caso de Sumpsi, passou pela sua aproximação à antropologia e, no de Rodrigues, pelo seu afastamento.

Seguramente inspirados pelo texto de convite, os autores discorrem sobre o métier de antropólogo-realizador ou realizador-antropólogo - que Sumpsi divide em três fases cronológicas distintas, em que transita de „visitante“ a „documentarista“ a „antropóloga“, e que Antunes estabelece em termos de uma experiência subjectiva do trabalho de campo que vai muito para além do que se pode mostrar, contar e, desde logo, ver (através das imagens). Se Sumpsi procura, na antropologia, o caminho para uma certa objectivação do visível, Antunes crê que as imagens ajudam a „experienciar“ tanto o objectivo como o subjectivo não-visíveis (i.e. o „real invisível“), e de uma outra forma, o que o leva a falar de uma ,antropologia do negativo visual“. Este autor estabelece a urgência do filmar, não só porque há coisas (rituais) que estão a desaparecer ou a renascer enquanto „espectáculo de valor etnográfico“ mas, sobretudo, porque o filme é assumido como projecto maior de representação da realidade (de realidades outras). É preciso filmar ponto, pronto. $\mathrm{O}$ mesmo acontece com os restantes realizadores. 
Um segundo tema transversal prende-se, efectivamente, com o lugar da antropologia na produção de um documentário visual (i.e. no processo criativo), que remete para a clássica tensão real/ciência vs. ficção/arte e onde situamos igualmente as questões da subjectividade e da objectividade. Decorrente deste tema aparece a reflexão sobre a „antropologicidade“ dos filmes; i.e., sobre o seu potencial de representação em termos de cientificidade do registo. Estão em causa questões de representação num duplo sentido. Falamos de questões relativas à procura e preservação de uma certa integralidade (e integridade?) da realidade, que Sumpsi pretende resolver com a opção metodológica e ética pelo documentário longitudinal. Mas também, concomitantemente, de questões que se prendem com as políticas de representação, incidindo sobre aspectos como a auto-representação e o controlo da representação pelos sujeitos filmados (Wateau; Lacerda), a recusa de códigos exoticisantes (Antunes), e a afirmação do vídeo como objecto político (Lacerda) ou veículo de conhecimento de processos de mudança social (Sumpsi; Rodrigues) ou transição existencial (Antunes). Em qualquer um dos casos, a relação entre o documentarista/ etnógrafo e os sujeitos filmados é central. A desejada intimidade com estes é procurada, no caso de Sumpsi, numa forma de filmar com tempo, em „lume brando“, que todavia parece levar a autora a ingenuamente acreditar que se limitara a observar „de uma forma completamente objectiva“ e „sem manipular factores“. Para Wateau a intimidade é garantida pelo trabalho de campo prévio, sem câmara de filmar, o que lhe permite partilhar a autoria do projecto com Vânia, a protagonista de Ma Parenté Au Village (2011,18'), que nos conduz ao longo de uma demanda junto dos seus familiares na Aldeia da Luz (Alentejo, Sul de Portugal). O uso de um tema clássico da antropologia (o parentesco) é-nos apresentado como um meio e não um fim em si mesmo, i.e. como um „modo de acesso às populações“, e não um estudo exaustivo, passível de ser visto como „completo“.

Estamos, portanto, a falar de um plano ao mesmo tempo, metodológico, epistemológico, político e ético que finalmente culmina nas reflexões, presentes em todos os artigos, sobre a recepção dos filmes. Para quem é feito o filme? - pergunta directa e explicitamente Wateau, afirmando que o seu $M a$ Paranté au Village é feito para públicos, deliberadamente no plural, mas não para a televisão. A autora reivindica outros contextos de recepção - e espectadoria, portanto. $\mathrm{Na}$ realidade, todos os realizadores apontam para esse cúmulo, na vida social das suas obras: o momento em que se emancipam do criador e ganham vida própria. $\mathrm{Na}$ antropologia, a partilha com os sujeitos filmados, num acto de reciprocidade ética, é condição da representação, garantindo a validade emic do produto final.

Finalmente, a dicotomia visibilidade/invisibilidade aparece igualmente reflectida nos cinco textos, a partir, por exemplo, da discussão das virtudes metafóricas da imagem. Ou seja, como pode a materialidade do visível garantir a representação de algo que não está presente ou que não tem representação visual? $\mathrm{Ou}$, em alternativa, nas palavras de Antunes, „como materializar visualmente o invisível“? Falamos do passado vivido e da nostalgia (ou ,jugonostalgia“), como no caso de Rodrigues; da vida para além da morte, na abordagem de Antunes; ou mesmo da configuração patrimonial de um forte que (já) não o é, como no caso de Sumpsi. O encontro e a confrontação com esta dicotomia aparece também sob a forma de questionação de tudo o que fica sem ser mostrado apesar de ser dito: a síntese háptica e corpórea que procura Lacerda; o parentesco contado por Wateau, através de Vânia. Portanto, situamos também aqui as dimensões materiais e imateriais da vida humana enquanto cultura em continuado processo de fabricação.

Em conclusão, enquanto lados avessos de filmes, os cinco textos permitem-nos aceder à ideia de contraponto que, qual metáfora musical, nos garante a complementaridade de duas 
composições tocadas em conjunto. Texto e vídeo, vídeo e texto, representações complementares e alternativas da realidade, garantem-nos esta possibilidade. Através das palavras, nos artigos deste dossier, os realizadores revelam-nos os lados outros do seu processo criativo. O que textos e filmes não deixam de sugerir é que, apesar de tudo, como em qualquer forma de representação (e numa necessária ressalva ao que foi dito) um certo grau de „redução“ é inevitável. A experiência humana nunca se esgota em imagens ou palavras. É sempre muito maior do que um texto ou um filme, ou os dois em simultâneo. 